\title{
RESPONSABILIDADE SOCIAL CORPORATIVA: UMA DISCUSSÃO A RESPEITO DA EPISTEMOLOGIA SUBJACENTE AOS CONCEITOS UTILIZADOS NA ÁREA
}

\author{
Rebeca de Moraes Ribeiro de Barcellos \\ rebecamribeiro@gmail.com \\ Universidade Federal de Santa Catarina - Florianópolis, SC/Brasil \\ Eloise Livramento Dellagnelo \\ eloise@cse.ufsc.br \\ Universidade Federal de Santa Catarina - Florianópolis, SC/Brasil
}

Recebido em 28/07/2011

Aprovado em 04/10/2012

Disponibilizado em 01/04/2013

Avaliado pelo sistema double blind review

Revista Eletrônica de Administração

Editor: Luís Felipe Nascimento

ISSN 1413-2311 (versão on-line)

Editada pela Escola de Administração da Universidade Federal do Rio Grande do Sul.

Periodicidade: Quadrimestral

Sistema requerido: Adobe Acrobat Reader.

\section{RESUMO}

Considerando a importância da análise epistemológica na produção do conhecimento científico em qualquer área em termos gerais e na administração em termos particulares, o presente artigo se propõe a analisar os fundamentos epistemológicos de um dos temas que vem ganhando relevância no contexto da produção acadêmica em administração: a Responsabilidade Social Corporativa. A partir do estudo desenvolvido por Moretti e Campanário (2009), o qual mapeou as principais referências bibliográficas utilizadas para fundamentar os trabalhos apresentados sobre a temática nos Encontros Nacionais da Anpad, foram selecionadas oito obras referenciadas, as quais estavam relacionadas especificamente aos fundamentos da responsabilidade social e analisaram-se os trechos que tratam dos motivos pelos quais as empresas praticam ações de responsabilidade social. Posteriormente, as obras foram analisadas sob a ótica das principais correntes epistemológicas do séc. XX, consideradas relevantes para a compreensão do fenômeno: empirismo, racionalismo, utilitarismo, positivismo, funcionalismo e dialética. As conclusões apontam para o fato de que, além da existência de uma zona de conforto intelectual nos estudos sobre o assunto, já apontadas por Moretti e Campanário (2009), o embasamento das referências utilizadas está centrado na lógica de operar do paradigma dominante nas ciências da administração, ressaltando o caráter funcionalista e utilitarista das práticas de responsabilidade social por parte das empresas. Curiosamente, os estudos não puderam ser classificados como empiristas, racionalistas ou positivistas devido à falta de dados concretos que fundamentassem as conclusões dos autores, com exceção da obra de Freeman (1999) a qual apresenta bases empíricas a partir das quais as conclusões são auferidas. As conclusões chamam a atenção para as dificuldades de desenvolvimento de um campo de pesquisas centrado em poucas obras e com fundamentos epistemológicos restritos e não explicitados, levantando a necessidade de proposição de pesquisas que, utilizando-se de diferentes pressupostos epistemológicos, REAd I Porto Alegre - Edição 74 - N 1 - jan/abr 2013 - p. 35-60 
Responsabilidade social corporativa: uma discussão a respeito da epistemologia subjacente aos conceitos utilizados na área

possam descrever o fenômeno de forma mais precisa, contribuindo para uma compreensão reflexiva da atuação das organizações empresariais no campo social.

Palavras-chave: Responsabilidade Social Corporativa; Epistemologia; Estudos Organizacionais.

\title{
CORPORATE SOCIAL RESPONSIBILITY: A DISCUSSION ON THE EPISTEMOLOGY UNDERLYING THE CONCEPTS USED IN THE AREA
}

\begin{abstract}
Considering the importance of epistemological analysis in the production of scientific knowledge in any area in general and in administration in particular terms, this article aims to analyze the epistemological foundations of one of the themes that has been gaining importance in the context of academic research in management: Corporate Social Responsibility. Inspired by the study developed by Moretti and Campanário (2009), which mapped the primary references used to substantiate the works presented on the topic during Enanpads, we selected eight works referenced, which were specifically related to the foundations of social responsibility and analyzed the sections dealing with the reasons why companies practice social responsibility. Later, the works were analyzed from the perspective of the main epistemological thoughts in XXth century, considered relevant for understanding the phenomenon: empiricism, rationalism, utilitarianism, positivism, functionalism and dialectics. The conclusions point to the fact that, besides the existence of an intellectual comfort zone in the studies on the subject, as pointed out by Moretti and Campanário (2009), the foundation of the references used is centered on logic of the dominant paradigm in administration studies, highlighting the functionalist and utilitarian character of social responsibility's practices made by companies. Interestingly, the studies could not be classified as empiricist, rationalist or positivist due to lack of concrete evidence to substantiate the authors' conclusions, except for the work of Freeman (1999) which presents an empirical basis from which conclusions are received. The findings draw attention to the difficulties of developing a field of research focused on few works, with non-explicit and restricted epistemological options, raising the need for research using different epistemological assumptions to describe the phenomenon more accurately, contributing to a reflective understanding of the role of business organizations in the social field.
\end{abstract}

Keywords: Corporate Social Responsibility; Epistemology; Organizational Studies.

\section{INTRODUÇAO}

A epistemologia consiste, de acordo com Japiassu (1991, p.16), no "estudo metódico e reflexivo do saber, de sua organização, de sua formação, de seu desenvolvimento, de seu funcionamento e de seus produtos intelectuais." A função desta análise é submeter a prática dos cientistas a uma reflexão que toma por objeto uma ciência em seu processo de gênese. 
Rebeca de Moraes Ribeiro de Barcellos \& Eloise Livramento Dellagnelo

(JAPIASSU, 1991) Como qualquer área de conhecimento, é importante que a administração, como ciência, também seja analisada a partir de um olhar epistemológico, na busca da compreensão dos modelos de mundo que estão intrínsecos à sua produção, no entendimento da validade e das limitações do conhecimento produzido e reproduzido. Neste sentido, Garcia e Bronzo (2000, p.1) afirmam que "o que verdadeiramente se impõe como desafio para a Teoria Social é a observação dos limites e das mediações complexas que se interpõem, inevitavelmente, na atividade prática do pesquisador." Para estes autores, fragmentação e descontinuidade são características da natureza multidisciplinar da administração, campo que está sujeito a contribuições metodológicas e conceituais de diversas áreas do conhecimento.

A análise epistemológica dos estudos organizacionais é recente, apontam Garcia e Bronzo (2000), sendo os primeiros estudos nesta área encontrados há cerca de quarenta anos, para uma ciência que surge por volta do início do século XX. Desde este período

“... apesar das diferentes escolas de pensamento, os estudos na Administração não se
inclinaram devidamente ao questionamento e à proposição de alternativas
pragmáticas para o problema das relações de poder e dominação nos contextos
organizacionais. Encontramo-nos hoje, porém, em uma situação característica
limítrofe, em que os antigos valores formais e teóricos mostram-se limitados para
responder os desafios recentes ensejados à prática administrativa." (GARCIA e
BRONZO, 2000. p. 4)

Dada a importância da reflexão epistemológica acerca da construção dos saberes em administração, o presente trabalho analisa as bases epistemológicas na produção acadêmica brasileira em torno do tema Responsabilidade Social Corporativa. Freire et al (2008) mostram que o assunto vem conquistando espaço considerável de discussão e de reflexão na academia e no ambiente empresarial, sendo que o número de artigos publicados no país sobre o tema evolui de onze na década de 90 para 282 no período de 2000 a 2007, representando um enorme salto quantitativo. No entanto, opõem Moretti e Campanário (2009), o aspecto qualitativo da produção deve ser analisado com maior profundidade, pois existe uma fragmentação na produção por autores e a área recorre a expedientes ainda tradicionais de referências gerais com pouca contribuição para um aprofundamento específico do tema. Os autores apontam para um forte componente reprodutor nos estudos publicados nos Encontros Nacionais da Associação Nacional de Pós-Graduação em Administração - Enanpad - baseados em um reduzido espectro de referenciais teóricos, os quais apresentam esquemas interpretativos a partir de abordagens estrangeiras sobre o tema, revelando o que os autores chamam de síndrome de zona de conforto intelectual nas pesquisas sobre o assunto.

REAd I Porto Alegre - Edição 74 - N 1 - jan/abr 2013 - p. 35-60 
Responsabilidade social corporativa: uma discussão a respeito da epistemologia subjacente aos conceitos utilizados na área

Neste sentido, Moretti e Campanário (2009) mapeiam a existência de quinze referências principais, recorrentes nos artigos publicados nos Enanpads nos períodos de 1997 a 2007, período relatado por Freire et al (2008) como o de maior crescimento quantitativo de publicações sobre o assunto no Brasil. Considerando a relevância que o tema vem ganhando nos estudos organizacionais, o lugar de destaque ocupado pelo Enanpad como referência na produção acadêmica em administração e o mapeamento dos principais autores tratados nas publicações sobre Responsabilidade Social neste espaço acadêmico, resta compreender quais são as bases epistemológicas sobre as quais estão assentadas as pesquisas que estão formatando o corpo teórico de conhecimentos sobre o assunto no Brasil. Moretti e Campanário (2009, p.82) afirmam que "é necessário um debate acadêmico dirigido para o estabelecimento de uma agenda de pesquisas que possibilite sustentar o desenvolvimento conceitual da RSE, principalmente devido a sua natureza de se valer de linhas epistemológicas diversas."

O objetivo do presente trabalho é, portanto, analisar os fundamentos epistemológicos das principais referências mencionadas nos estudos sobre Responsabilidade Social Corporativa publicados nos Enanpad, no período de 1997 a 2007, conforme mapeados por Moretti e Campanário (2009). Para isto, apresentar-se-á uma breve revisão das principais correntes epistemológicas do século XX que podem ajudar a compreender o delineamento que o assunto vem adquirindo no campo e os fundamentos do pensamento de oito autores mapeados pelo trabalho de Moretti e Campanário (2009), os quais abordam especificamente o tema da Responsabilidade Social Corporativa. Em seguida, será apresentada a análise categorial, técnica de análise de conteúdo, realizada sobre produção em questão, cujas categorias foram elaboradas a partir das características das correntes epistemológicas apresentadas, em busca de compreender os fundamentos epistemológicos que estão por trás da produção acadêmica em Responsabilidade Social no campo da Administração no Brasil. Finalmente, apresentam-se as conclusões que foram alcançadas com o estudo.

\section{REFERENCIAL TEÓRICO: CORRENTES EPISTEMOLÓGICAS NA MODERNIDADE}

Os séculos XV e XVI foram marcados por profundas transformações na sociedade em direção ao sistema-mundo que observamos atualmente. O surgimento da ciência, tal como é 
Rebeca de Moraes Ribeiro de Barcellos \& Eloise Livramento Dellagnelo conhecida hoje, é um dos marcos deste período, influenciando profundamente costumes, culturas, formas de pensar e maneiras de se relacionar do homem com o seu ambiente. Naquele momento, a humanidade buscava um sistema alternativo ao sistema religioso predominante, regido por leis e crenças espirituais, que governavam a vida dos homens, determinavam as leis da natureza, regulavam as colheitas e plantações. O Renascimento é o movimento cultural e intelectual que marca este período de transição. É neste período também que começa a se delinear o sistema econômico que viria a dominar todo o planeta: o capitalismo. As relações entre a nova ciência que se estabelece e o novo sistema econômico são perceptíveis e constituem uma complexa tessitura de descobertas, crenças e interesses que se faz verificar até os dias de hoje.

O surgimento da ciência moderna está vinculado ao surgimento das correntes epistemológicas denominadas empirismo e positivismo. O empirismo tem em Francis Bacon seu maior expoente. Para Bacon (1979), a melhor demonstração é a experiência proporcionada por um experimento rigoroso, cuja aplicação a situações semelhantes deve decorrer de procedimento metódico. Desta forma, só é real aquilo que pode ser experimentado e a ciência se constitui, assim, na capacidade de repetir estes experimentos, a fim de conhecer a natureza para, em última instância, controlá-la. A busca do homem, como a da ciência, neste contexto é desvendar as leis da natureza para dominá-la e utilizá-la a seu favor, ou de acordo com seus interesses. De acordo com Bacon (1979), a interpretação da natureza constitui-se de duas etapas gerais: o estabelecimento de axiomas oriundos da experiência e a dedução e derivação de novos experimentos a partir dos axiomas estabelecidos. O método proposto defende a dedução como chave para a interpretação, decorrentes do estabelecimento de critérios de essência, de desvio e de comparação. Procedendo desta forma, o cientista transcende a razão por meio da experiência, aplicando o que se chamou de Empirismo.

Já com Descartes (1979) encontramos a busca pela aplicação da razão à investigação, sendo que, de acordo com a sua concepção, a primeira consiste no único meio de proporcionar o verdadeiro conhecimento, motivo pelo qual se denominou a esta forma de proceder Racionalismo. Embora não refute o empirismo e a necessidade de se comprovar a realidade por meio de experimentos, Descartes (1979) insiste na importância da razão humana para o processo de construção do conhecimento científico, já que este não poderia se realizar senão por intermédio e intervenção do cientista.

REAd I Porto Alegre - Edição 74 - N 1 - jan/abr 2013 - p. 35-60 
Responsabilidade social corporativa: uma discussão a respeito da epistemologia subjacente aos conceitos utilizados na área

Inserido no contexto da Revolução Industrial que começava a alterar radicalmente a forma de produção de bens e as relações sociais vigentes na Inglaterra do século XVI, Jeremy Bentham (1979) propõe o princípio da utilidade, noção que constituirá o fundamento da corrente filosófica utilitarista. Baseia-se na concepção de que as decisões humanas são sempre pautadas por dois aspectos, quais sejam o prazer e a dor, sendo que o princípio da utilidade consiste em maximizar o prazer e/ou minimizar a dor. Para Bentham (1979), a utilidade constitui a única razão que explica porque uma determinada ação pode ou deve ser praticada. Como não poderia deixar de ser, a concepção de Bentham está estreitamente alinhada ao momento histórico por ele vivenciado e às noções sociais e morais que lançam as bases do modo de produção capitalista calcado na racionalidade instrumental. Neste sentido, nenhuma ação faria sentido, ou seria compreendida ou justificada por razões intrínsecas, aspecto próprio da racionalidade substantiva.

É também neste período histórico que surge o Positivismo, corrente filosófica que, de acordo com Padovani e Castagnola (1990) ocupa a segunda metade do século XIX, baseandose em princípios contrários ao idealismo, postulando que a única fonte de conhecimentos e critérios de verdade são a experiência, os dados positivos, os dados sensíveis. Reduz o conhecimento humano ao conhecimento sensível, a metafísica à ciência e o espírito à natureza. Apresenta uma concepção considerada hedonista e utilitária da realidade dos fatos, assumindo uma perspectiva progressista e naturalística da evolução, em direção ao bem-estar material. Para o positivismo, a única realidade existente, o que é passível de se conhecer, é a realidade física que se pode atingir cientificamente. Sob esta égide, Augusto Comte é considerado o maior positivista francês, para quem a ciência deveria substituir a filosofia, tendo como objetivo dos processos investigativos a fixação de leis sempre mais gerais (lógica indutiva) e as relações constantes de sucessão ou de semelhança entre os fatos entendidos positivistamente. Na Inglaterra, Herbert Spencer é o sistematizador e divulgador do positivismo. O principal aspecto da obra de Spencer é a aplicação da lei da evolução a todo campo da experiência, baseando-se na concepção de seleção natural, segundo a qual os organismos mais fortes se adaptam ao meio ambiente e sobrevivem (PADOVANI E CASTAGNOLA, 1990).

A corrente positivista tem um papel fundamental na evolução da ciência. O empirismo como premissa e a importância atribuída ao dado são, certamente, características sem as quais 
Rebeca de Moraes Ribeiro de Barcellos \& Eloise Livramento Dellagnelo

muitos dos avanços conquistados pela ciência contemporânea seriam impossíveis. Como assinalam Guba e Lincoln (1994), as ciências sociais, tradicionalmente consideradas em oposição às ciências naturais em cujo seio se desenvolveu a concepção positivista, também foram beneficiadas por suas considerações, no momento em que insere em seu contexto a necessidade de verificação, a perspectiva de se transcender o teoreticismo e buscar ferramentas para se proceder a análises empíricas a partir de proposições intelectuais.

Numa perspectiva incremental, verifica-se que as ideias utilitaristas e positivistas fundamentam novos olhares filosóficos e epistemológicos, construindo as estruturas intelectuais sobre as quais se fundamentam as correntes que se sucedem, dentre as quais se encontra o Funcionalismo. As raízes do funcionalismo são encontradas na sociologia de Durkheim. Duas definições deste autor são particularmente importantes para a abordagem funcionalista: a de fato social e a função da divisão do trabalho. Para Durkheim (1978, p.88), fatos sociais "consistem em maneiras de agir, pensar e sentir exteriores ao indivíduo, e dotadas de um poder coercitivo em virtude do qual se lhe impõem." Portanto, os fatos sociais devem ser tratados como coisas. Ao tratar da função da divisão do trabalho, Durkheim (1978) introduz o conceito de função ligado à satisfação de uma necessidade a qual ela corresponde.

Sob a influência dos trabalhos de Durkheim e Spencer, Malinowski (1970) estrutura as principais definições e abrangências do funcionalismo, afirmando que neste se encontram os únicos critérios válidos de identificação cultural. Postula o autor que todo aspecto de uma cultura, sejam suas instituições, simbolismos, artefatos, entre outros, tem uma função. A função, para Malinowski (1970) significa a satisfação de uma necessidade, que pode ser biológica, derivada ou integrativa. Para Radcliffe-Brown (1973, p.223), a função é a parte que um indivíduo "desempenha na vida social como um todo e, portanto, a contribuição que faz para a manutenção da continuidade estrutural." O sistema social é, segundo sua análise, considerado da mesma forma que um sistema orgânico. $\mathrm{O}$ funcionalismo procura dar um caráter positivista à análise dos sistemas sociais, sistematizando e organizando a observação dos fenômenos e fatos de forma a relacioná-los à satisfação de necessidades básicas deste sistema.

Buckley (1967) critica a predominância da perspectiva funcionalista na análise dos sistemas sociais. Para ele, a comparação com os sistemas orgânicos é inadequada, posto que a) os sistemas sociais não tem limites à adaptação estrutural, diferentemente dos orgânicos; b) não existe nos sistemas socioculturais uma estrutura específica, como nas espécies biológicas. 
Responsabilidade social corporativa: uma discussão a respeito da epistemologia subjacente aos conceitos utilizados na área

Para Buckley (1967), os sistemas socioculturais são inerentemente elaboradores e modificadores de estruturas, motivo pelo qual se torna relevante uma abordagem de processo na sua análise, incorporando a perspectiva de que a "aberração" é parte integrante do sistema e constitui, ao lado da estrutura normativa consensual, um equilíbrio auto mantenedor, que não é constante em virtude das diversas forças dinâmicas que atuam sobre estes sistemas.

As concepções analisadas neste ínterim compartilham de uma visão de mundo baseada nos princípios empiristas e positivistas. São ainda as correntes dominantes no pensamento científico atual, constituindo o que Souza Santos (1998) chama de paradigma vigente, dentro da concepção de paradigma cunhada por Thomas Khun. Argumenta Souza Santos (1998) que o paradigma cientifico estabelecido entre o século XVII e o século XX está em processo de transição, em vias de ser substituído por uma nova concepção, sobre a qual ainda temos somente especulações. Tal transformação decorre, na visão do autor, de uma crise profunda e irreversível do paradigma dominante, consequente da identificação de seus limites e insuficiências estruturais.

O esgotamento do paradigma vigente dá-se, sobretudo, pelo estabelecimento de novas necessidades acerca do saber, fundado em critérios que possam expandir o espectro de atuação da ciência a fim de conferir-lhe um caráter mais abrangente, completo, complexo e, sobretudo, socialmente relevante. A convergência entre os métodos antes apartados em ciências naturais e ciências sociais vem demonstrando a inexistência de uma linha separatória definitiva entre homem e natureza, observador e objeto, caos e ordem. Não significa, no entanto, afirmar que a atual concepção de mundo construída pela ciência será completamente abandonada, tampouco seus métodos. Convém conceber que a própria distinção entre a aplicabilidade e inaplicabilidade de certo modelo pode ser, sob a égide de um novo paradigma, reducionista e arbitrária, na medida em que o conceito de verdade se redefine muito mais em função de processos do que de resultados. A construção de novos modelos passa pela incorporação e reformulação dos conhecimentos construídos até agora, a partir de uma perspectiva crítica, socialmente relevante, ecologicamente sustentável e humanamente profícua.

Neste contexto de considerações acerca de um paradigma emergente, algumas ideias importantes do início do século passado têm sido revalorizadas na construção do conhecimento científico, como o método dialético. A dialética é também conhecida como a 
Rebeca de Moraes Ribeiro de Barcellos \& Eloise Livramento Dellagnelo

filosofia da contradição e encontra em Hegel e Marx seus principais expoentes (FOULQUIÉ, 1978). Gurvitch (1987, p.32) define a dialética como

O caminho tomado pelo humano em movimento para combater os obstáculos que as totalidades reais em movimento encontram em seu caminho, assim como para apreendê-las e conhece-las, aí se incluindo, ao lado da realidade social, os conjuntos conceituais ou reais que levam, de forma próxima ou longínqua, a sua marca.

A lógica dialética está centrada no estudo e compreensão do conteúdo, além da forma, e não exclusivamente desta última, como é característico da lógica formal (LEFEBVRE, 1983). A perspectiva da lógica dialética, ou concreta, define que "os instrumentos do pensamento não podem ser separados dos objetos aos quais se aplicam", e "encontra-se ligada a uma concepção científica (racional) da história" (LEFEBVRE, 1983, p. 88). Foulquié (1978) e Gurvitch (1987) apresentam os princípios gerais da dialética. O primeiro é a compreensão de haver uma interdependência ativa entre as diversas partes do real, visando simultaneamente às totalidades e às partes. Em segundo lugar, a aceitação de que o real implica contradições intrínsecas, de forma que o método dialético é sempre negação. $\mathrm{O}$ terceiro ponto é o abalo de toda estabilização aparente na realidade social, considerando que o movimento e o devir da matéria são criadores de algo novo. Deste terceiro, conclui-se um quarto aspecto que é o caráter provisório da verdade vinculado a uma fase histórica do pensamento na tentativa de explicar o mundo.

Em síntese, apresentamos no quadro a seguir as principais correntes epistemológicas discutidas neste trabalho, com os conceitos centrais destacados a partir dos autores estudados.

Quadro 1 - Correntes epistemológicas e conceitos centrais

\begin{tabular}{|l|l|l|}
\hline Corrente epistemológica & Conceito Central & Autores em destaque \\
\hline Empirismo & $\begin{array}{l}\text { Só é real aquilo que pode ser experimentado e a } \\
\text { ciência se constitui, assim, na capacidade de } \\
\text { repetir estes experimentos, a fim de conhecer a } \\
\text { natureza. }\end{array}$ & \\
\hline Racionalismo & $\begin{array}{l}\text { Sem refutar o empirismo, destaca a importância } \\
\text { da razão humana para o processo de construção } \\
\text { do conhecimento científico, já que este não } \\
\text { poderia se realizar senão por intermédio e } \\
\text { intervenção do cientista. }\end{array}$ & \\
\hline Utilitarismo & $\begin{array}{l}\text { O princípio da utilidade consiste em maximizar o } \\
\text { prazer e/ou minimizar a dor. A utilidade constitui } \\
\text { a única razão que explica porque uma } \\
\text { determinada ação pode ou deve ser praticada. }\end{array}$ & \\
\hline Positivismo & $\begin{array}{l}\text { A única fonte de conhecimentos e critérios de } \\
\text { verdade é a experiência, os dados positivos, os } \\
\text { dados sensíveis. }\end{array}$ & Augusto Comte e Herbert \\
Spencer
\end{tabular}

REAd I Porto Alegre - Edição 74 - N 1 - jan/abr 2013 - p. 35-60 
Responsabilidade social corporativa: uma discussão a respeito da epistemologia subjacente aos conceitos utilizados na área

\begin{tabular}{|l|l|l|l|}
\hline & $\begin{array}{l}\text { desempenha na vida social como um todo e, } \\
\text { portanto, a contribuição que faz para a } \\
\text { manutenção da continuidade estrutural. }\end{array}$ & Brown. \\
\hline Dialética & $\begin{array}{l}\text { Interdependência entre as partes; o real é } \\
\text { contraditório; o movimento e o devir são } \\
\text { criadores de algo novo. }\end{array}$ & $\begin{array}{l}\text { Foulquié, Gurvitch, } \\
\text { Lefebvre. }\end{array}$ \\
\hline
\end{tabular}
Fonte: elaborado pelas autoras

\section{PROCEDIMENTOS METODOLÓGICOS}

Levando-se em consideração o objeto de estudo deste trabalho, a estratégia de pesquisa mais adequada para a sua abordagem é a qualitativa. A pesquisa qualitativa pode ser definida como "a que se fundamenta principalmente em análises qualitativas, caracterizandose, em princípio, pela não utilização de instrumental estatístico na análise dos dados" (VIEIRA, 2004, p.17) Este tipo de análise tem por base conhecimentos teóricos e empíricos que permitem conferir-lhe cientificidade. Para Denzin e Lincoln (2006), a pesquisa qualitativa consiste num conjunto de práticas materiais e interpretativas que dão visibilidade ao mundo, na tentativa de entender ou interpretar os fenômenos em termos dos significados que as pessoas a eles conferem.

Tomando por base os destaques acerca das correntes epistemológicas apresentadas, definimos as categorias a serem utilizadas na análise do material selecionado nesta pesquisa, quais foram: a) bases empíricas dos estudos, possibilidades de reprodução dos mesmos (empirismo e positivismo); b) a perspectiva de utilidade do fenômeno em análise (utilitarismo); c) abordagem objetiva $x$ subjetiva da realidade (racionalismo); d) o caráter funcional do tema (funcionalismo); e) tratamento às tensões, contradições presentes (dialética).

O objetivo da análise a partir destas categorias é classificar o material analisado de acordo com as características das diferentes correntes epistemológicas. Para isso, definiu-se como universo de estudo as obras apontadas por Moretti e Campanário (2009) como as principais referências específicas relacionadas à Responsabilidade Social, utilizadas pelos autores de publicações acerca do tema nos Encontros Nacionais da Anpad, realizados de 1997 a 2007 (Quadro 2). Entendemos, assim como Moretti e Campanário (2009, p.71) que "a produção no Enanpad estabelece novas referências conceituais para RSE" e "o Enanpad é parte importante da produção intelectual brasileira sobre RSE", de forma que o evento constitui uma importante amostra do desenvolvimento cientifico neste tema em nosso país.

REAd I Porto Alegre - Edição 74 - N 1 - jan/abr 2013 - p. 35-60 
Rebeca de Moraes Ribeiro de Barcellos \& Eloise Livramento Dellagnelo

Na seleção do corpus de análise, foram consideradas apenas as referências sobre o tema responsabilidade social, citadas nos estudos relacionados aos fundamentos do tema. Este estudo adotou como critério norteador da seleção dos trechos das obras mencionadas aqueles nos quais os autores discutiam o motivo pelos quais as empresas adotam práticas de responsabilidade social, assunto abordado em todas as obras analisadas.

Depois de selecionados os trechos, de acordo com o critério acima relatado, o material foi tratado com base na análise de conteúdo, especificamente pela técnica de análise categorial, a qual de acordo com Bardin (2004) consiste em dividir o texto em unidades, em categorias segundo reagrupamentos analógicos. As categorias reúnem um grupo de elementos em razão das características que estes elementos possuem em comum, No caso deste estudo, a categorização teve por base o critério semântico, a partir do qual os trechos foram classificados de acordo com as características das correntes epistemológicas mencionadas.

Cabe destacar que a obra organizada por Ashley já se encontra reeditada, sendo que a obra mais atual é a que está disponível para aquisição no mercado e, por isso, foi a segunda edição a analisada por ocasião deste trabalho. Da mesma forma, a versão de 2002 do Guia de Elaboração do Balanço Social elaborado pelo Instituto Ethos, não se encontra mais disponível para consulta na Internet, motivo pelo qual se analisou a versão de 2006.

Quadro 2 - Referências dos estudos sobre Responsabilidade Social

\begin{tabular}{|l|c|}
\hline \multicolumn{1}{|c|}{ Referência bibliográfica } & $\begin{array}{c}\text { Citações em trabalhos } \\
\text { publicados em Enanpad entre } \\
\text { 1997 e 2007 }\end{array}$ \\
\hline $\begin{array}{l}\text { ASHLEY, Patricia. Ética e responsabilidade social nos negócios. } \\
\text { São Paulo: Saraiva, 2001. }\end{array}$ & 19 \\
\hline $\begin{array}{l}\text { INSTITUTO ETHOS. Guia de elaboração do Balanço Social-2002. } \\
\text { Disponível em www.ethos.org.br }\end{array}$ & 19 \\
\hline $\begin{array}{l}\text { MELO NETO, F. P., FROES, C. Responsabilidade social e } \\
\text { cidadania empresarial. Rio de Janeiro: Qualitymark, 1999. }\end{array}$ \\
\hline $\begin{array}{l}\text { FREEMAN, R. Edward. Stakeholders, social responsibility, and } \\
\text { performance: empirical evidence and theoretical perspectives. } \\
\text { Academy of Management Journal. v.42, n.5, p.479-, oct. 1999. }\end{array}$ \\
\hline $\begin{array}{l}\text { PORTER, Michael. Green and Competitve: ending the stalemate. } \\
\text { Harvard Businnes Review. v. 73, n. 5, p. 120-134. Sep/Oct., 1995. }\end{array}$ \\
\hline $\begin{array}{l}\text { CARROL, Anchie B. A three-dimensional conceptual model of } \\
\text { corporate performance. Academy of Management Review. v.4, p. } \\
\text { 497-505, 1979. }\end{array}$ \\
\hline $\begin{array}{l}\text { VENTURA, E. Responsabilidade social das organizações: estudo } \\
\text { de caso no Banco Central do Brasil. Dissertação de Mestrado. Rio } \\
\text { de Janeiro: FGV/EBAPE, 1999. }\end{array}$ \\
\hline $\begin{array}{l}\text { FRIEDMAN, Milton. The social responsability of businnes is to } \\
\text { increase its profits. New York Times Magazine, September, 1970. }\end{array}$ \\
\hline
\end{tabular}

Fonte: adaptado de Moretti e Campanário (2009)

REAd I Porto Alegre - Edição 74 - N 1 - jan/abr 2013 - p. 35-60 
Responsabilidade social corporativa: uma discussão a respeito da epistemologia subjacente aos conceitos utilizados na área

\section{APRESENTAÇÃO DOS DADOS}

A primeira obra analisada foi o livro Ética e Responsabilidade Social nos Negócios, organizado por Patricia Ashley (2002). Nas primeiras páginas do livro encontra-se que a adoção de padrões éticos por parte das empresas é uma resposta ao funcionamento global da economia, o que exige padrões éticos e morais mais rigorosos das empresas, seja por necessidade de manter uma boa imagem, seja por demandas diretas do público. Neste contexto, afirma a autora, as empresas terão que "aprender a equacionar a necessidade de obter lucros, obedecer às leis, ter um comportamento ético e envolver-se em alguma forma de filantropia para com as comunidades em que se inserem.” (ASHLEY, 2005. p.6)

$\mathrm{Na}$ visão da autora, isso decorre de pressões econômicas e sociais exercidas pelo mercado globalizado sobre as empresas, afetando a forma como os negócios são feitos ao redor do mundo e alterando o papel do Estado. Conforme ASLHEY (2002, P. 7) "está se tornando hegemônica a visão de que os negócios devem ser feitos de forma ética, obedecendo a rigorosos valores morais, de acordo com comportamentos cada vez mais universalmente aceitos como apropriados." A perspectiva da utilidade de uma atuação socialmente responsável e a noção da função que esta tem para o desempenho da organização, ficam bem claras quando a autora afirma que "as organizações do terceiro milênio precisam ser socialmente responsáveis se quiserem sobreviver em meio à competição cada vez mais acirrada", assim a "preocupação com a responsabilidade social tornou-se um diferencial fundamental para tornar as organizações mais produtivas e garantir o respeito do público e, enfim, sua própria viabilidade" (ASLHEY, 2005. p.8) Segundo a autora, está havendo uma mudança de mentalidade nas empresas, que valoriza a boa conduta empresarial e, segundo a qual, "eficiência e lucro podem ser combinados com valores como cidadania, preservação ambiental e ética nos negócios." (ASHLEY, 2005. p.13) A autora entende que a empresa pode receber da sociedade o título de empresa cidadã, o que pode lhe trazer vantagens como o fortalecimento da sua imagem, capacidade de atrair talentos, maior comprometimento dos empregados, maior aceitação dos clientes, maior facilidade de acesso a financiamento e contribuição para legitimar a empresa perante o Estado e a sociedade, características que evidenciam o caráter utilitário das práticas sociais por parte das organizações. 
Rebeca de Moraes Ribeiro de Barcellos \& Eloise Livramento Dellagnelo

Explica-se também que há várias interpretações acerca da responsabilidade social e uma diversidade de ângulos a partir dos quais se pode analisar o fenômeno, embora os autores adotem uma linha central que leva a entender a responsabilidade social como uma função do negócio, da mesma forma que o cuidado com a qualidade, a marca e os produtos. Para Ashley (2005, p.71)

O principal motivo para uma empresa ser socialmente responsável é que isso
proporciona a ela consciência de si mesma e de suas interações na sociedade. Em um
mundo em que a realidade de mercado muda com velocidade cada vez maior, a
empresa precisa saber exatamente qual é sua missão, e a busca de um sentido ético
para sua existência deve voltar-se tanto às relações de mercado quanto às relações
além do mercado.

A segunda obra analisada foi o Guia de elaboração do Balanço Social - 2006, publicado pelo Instituto Ethos. Esta é uma publicação que não trata especificamente do tema responsabilidade social, e sim de um dos instrumentos de gestão e comunicação a ele relacionados: o balanço social, um relatório acerca da atuação da empresa de forma mais abrangente, envolvendo sua atuação em termos econômicos, sociais e ambientais.

Para o Instituto Ethos (2006, p.5), a iniciativa de publicar um balanço social vai ao encontro de dois objetivos: "o de ser uma ferramenta de gestão, o que permite uma melhor mensuração do desempenho de sua gestão sob a perspectiva da responsabilidade social, e o de ser uma ferramenta de diálogo com as partes interessadas que objetiva a construção e o refinamento contínuo do engajamento destas partes." Para isso, define o Instituto, a empresa deve entender que o balanço social é uma publicação que objetiva mais do que uma comunicação unidirecional. Entende-se que a publicação do relatório "é a oportunidade de a empresa compreender como as ações divulgadas estão em consonância com sua visão estratégica e com os compromissos estabelecidos por sua liderança em direção à sustentabilidade, além de abrir um espaço de conhecimento mais aprofundado sobre sua gestão, com a possibilidade de estreitar relações com diversos públicos" (INSTITUTO ETHOS, 2006. p.5). Aqui, como na obra de Ashley (2005), a perspectiva utilitarista aparece de forma clara, de maneira que as ações sociais devem estar em consonância com a visão estratégica da empresa, além de lhe possibilitar maior conhecimento e melhor relacionamento com diferentes públicos interessados. Destaca-se também na publicação seu caráter prescritivo, orientando que o relatório deve ser um instrumento de prestação de contas que reflita a realidade da prática organizacional, com as ações positivas e com os espaços para 
Responsabilidade social corporativa: uma discussão a respeito da epistemologia subjacente aos conceitos utilizados na área

correções e melhorias, atendendo à necessidade de informação dos diversos públicos interessados, e não uma peça publicitária de informação de boas ações.

Melo Neto e Froes (1999) conceituam a responsabilidade social em sua obra como uma decisão da empresa de participar de forma mais direta das ações comunitárias na região em que atua e minorar possíveis danos ambientais decorrentes do tipo de atividade que exerce. Os autores se baseiam na entrevista de um empresário ao jornal Gazeta Mercantil para explicitar os motivos pelos quais as empresas buscam ser socialmente responsáveis. Neste contexto, os autores afirmam que "se a empresa obtém recursos da sociedade, é seu dever restituí-los não apenas sob a forma de produtos e serviços comercializados, mas, principalmente, através de ações voltadas para a solução dos problemas que afligem esta sociedade.” (MELO NETO e FROES, 1999., p.78)

Por outro lado, os autores entendem que a responsabilidade social assume um caráter normativo para as empresas: "a empresa deve financiar projetos sociais porque é certo, justo e necessário assim proceder. É um mecanismo de compensação das 'perdas da sociedade' em termos de concessão de recursos para serem utilizados pela empresa" (MELO NETO e FROES, 1999., p.84). No entanto, assim como na maior parte das demais obras analisadas, os autores não apresentam dados empíricos que possam demonstrar de que forma estas compensações ocorrem na prática. A perspectiva utilitarista da Responsabilidade Social pode ser fortemente percebida quando Melo Neto e Froes (1999, p.156) afirmam que as "empresas desenvolvem projetos sociais com dois objetivos: exercer filantropia empresarial e desenvolver estratégias de marketing com base em ações sociais." Além disso, ressalvam os autores "o retorno social ocorre quando a maioria dos consumidores privilegia a atitude da empresa de investir em ações sociais e o desempenho da empresa obtém o reconhecimento do público", sendo retorno social entendido por eles como os "ganhos materiais e imateriais obtidos pela empresa investidora que canaliza recursos para projetos sociais e ações comunitárias.” (MELO NETO e FROES, 1999. p.166)

Analisou-se na sequência o artigo publicado por Freeman (1999), o qual possui base empírica e se refere a um apanhado de artigos enviados ao Academy of Management Journal, por ocasião de uma edição especial sobre o tema: stakeholders, responsabilidade social e performance corporativa. Foram analisados pelo autor diversos artigos, tendo sido reportados na obra em questão os seis considerados mais relevantes pelos revisores do periódico.

REAd I Porto Alegre - Edição 74 - N 1 - jan/abr 2013 - p. 35-60 
Rebeca de Moraes Ribeiro de Barcellos \& Eloise Livramento Dellagnelo

Para Freeman (1999), o interesse neste assunto tem sido disseminado por alguns fatores: i) aumento da sensibilidade para questões éticas entre indivíduos e organizações; ii) destaque por parte da mídia de problemas relacionados a danos ambientais, tratamento impróprio a empregados e danos aos consumidores causados por problemas de produção; iii) aumento da regulação governamental; iv) tomada de decisões de investidores levando em consideração a responsabilidade social, além do desempenho econômico; v) aumento da sensibilidade dos consumidores à performance social das empresas das quais eles adquirem produtos/serviços. Diante deste contexto, Freeman (1999, p.479) afirma uma visão bastante utilitarista e funcionalista da questão "gerenciar concorrentes interesses dos stakeholders é uma função gerencial primordial."

Nos estudos analisados por Freeman (1999), algumas conclusões são demonstradas, dentre as quais destacamos: a) na preocupação das empresas com seus stakeholders é dominante o foco estratégico, demonstrando uma perspectiva instrumental, sugerindo que a preocupação com os stakeholders é baseada na percepção de que isso pode melhorar o desempenho financeiro da empresa; b) apesar de a melhoria do nível dos serviços prestados aos consumidores ter uma influencia negativa sobre o lucro da empresa a curto prazo devido aos custos relacionados, tais melhorias estão associadas a aumentos no valor de mercado da empresa estudada, levando ao entendimento utilitário e funcional acerca da necessidade de melhoria dos serviços por parte das empresas.

O artigo de Porter (1995) foi o quarto analisado e trata da relação entre indicadores e metas de desempenho ambiental e a competitividade da empresa. Para o autor, a relação comumente estabelecida segundo a qual o cumprimento de metas ambientais por meio de processos de produção ambientalmente corretos elevaria custos e, portanto, diminuiria a competitividade, não é correta. O autor afirma que metas ambientais adequadamente desenhadas podem alavancar inovações que diminuam o custo total de um produto, determinando uma função específica para a gestão ambiental no contexto empresarial, a qual necessariamente redunda em benefícios para as empresas. O bom desempenho ambiental contribui para a competitividade na visão de Porter (1995), pois de acordo com seu ponto de vista, poluição é sinônimo de ineficiência, fazendo com que as empresas tenham que arcar com custos decorrentes do tratamento e da destinação adequada de seus dejetos industriais.

Porter (1995) argumenta que os gestores precisam reconhecer na melhoria ambiental uma oportunidade econômica e competitiva, e não um custo que incomoda ou uma meta REAd I Porto Alegre - Edição 74 - N 1 - jan/abr 2013 - p. 35-60 
Responsabilidade social corporativa: uma discussão a respeito da epistemologia subjacente aos conceitos utilizados na área

inevitável. As empresas, na visão dele, deveriam se questionar o quanto estão desperdiçando e o quanto poderiam agregar de valor ao consumidor, numa perspectiva claramente utilitária e funcionalista do papel da Responsabilidade Social nas empresas. O autor conclui afirmando que "ambientalistas, agências regulatórias e empresas bem-sucedidas rejeitarão a velha forma de fazer negócios e construir-se-ão sobre a nova lógica econômica que liga ambiente, produtividade de recursos, inovação e competitividade" (PORTER, 1995. p. 134).

A obra de Carrol (1979) é uma das pioneiras e mais referenciadas nos trabalhos sobre Responsabilidade Social Corporativa. Carrol realiza em 1979 um resgate acerca da literatura publicada até aquele momento em torno do tema. A partir da análise de várias definições, ele propõe um modelo com quatro categorias envolvidas nas responsabilidades de uma empresa para com a sociedade. $\mathrm{O}$ autor afirma que para se chegar a uma definição de responsabilidade social que atenda plenamente toda a gama de obrigações que uma empresa tem perante a sociedade, devem-se abordar as categorias legais, econômicas, éticas e discricionárias do desempenho empresarial, sendo que a história dos negócios demonstra que se privilegiam primeiramente os aspectos econômicos e legais.

As responsabilidades econômicas são, na visão de Carrol (1979), as primeiras e mais importantes responsabilidades de uma empresa para com a sociedade. Conforme o autor, a empresa é a unidade econômica básica da sociedade e sua responsabilidade é produzir produtos e serviços que esta deseja, auferindo lucros com isso, perspectiva eminentemente utilitarista. Carrol (1979) defende que o modelo de quatro categorias pode ajudar a identificar os motivos das ações realizadas pelas empresas, mas não discute, por exemplo, as contradições inerentes a estas categorias. Carrol (1979) aponta os cinco principais fatores levados em consideração pelos executivos na hora de definir as ações sociais da empresa, os quais demonstram uma visão utilitarista e funcionalista da prática. São eles: 1) combinar a necessidade social com uma necessidade da empresa; 2) seriedade da necessidade social; 3) o interesse dos altos executivos; 4) o valor da ação social em termos de relações públicas; 5) a pressão governamental.

A dissertação de Ventura (1999), diferentemente da maior parte das obras analisadas, tem um caráter mais empirista, utilizando como base o caso do Banco Central do Brasil. No entanto, o capítulo que trata da motivação das empresas para o exercício da responsabilidade social não apresenta nenhum dado concreto embasando suas afirmações. Para a autora, a 
Rebeca de Moraes Ribeiro de Barcellos \& Eloise Livramento Dellagnelo

motivação da empresa pode variar desde a percepção da responsabilidade social como investimento até a percepção como questão de cidadania.

Porém, deve-se ter em mente que um fator não exclui o outro, necessariamente, pois, muito embora a organização possa se utilizar da responsabilidade social como estratégia de ação, ao transformá-la em oportunidade, ainda assim, resulta em benefícios para a sociedade. Consideramos, então, que uma organização pode agir pelas duas motivações, sendo as duas igualmente legítimas. (VENTURA, 1999. p. 48)

Ventura (1999) aponta que o exercício da responsabilidade social de forma transparente, independente e ética, vinculado a alguma prioridade social, pode trazer ganhos à empresa em termos de valor agregado à imagem, novamente resgatando a perspectiva utilitarista. Com enfoque predominantemente funcionalista, são apresentadas como vantagens da adoção de práticas socialmente responsáveis a motivação dos funcionários pelo aumento da autoestima relacionado à imagem da organização, o desenvolvimento de lideranças internas nas ações em parceria com o terceiro setor e a consolidação de valores de solidariedade na empresa, vistos como catalisadores e estimuladores da formação de equipes. Embora Ventura (1999. p.50) destaque que "todos os stakeholders da organização ganham com sua responsabilidade social, num círculo virtuoso que, se não rompido, pode contribuir para o desenvolvimento sustentável", a autora ressalva que, a longo prazo, as maiores beneficiárias são as próprias empresas.

Especificamente no estudo desenvolvido sobre a responsabilidade social do Bacen, Ventura (1999, p.89) identifica:

O aumento do interesse do cidadão brasileiro por assuntos econômicos a partir do
Plano Real, a maior nitidez no que concerne a benefícios ou prejuízos que a
condução de uma política econômica pode trazer para a vida da população, o
aumento da conscientização de direitos de consumidores em relação aos bancos e a
maior cobrança social, principalmente por meio da imprensa, são fatores exigindo o
fortalecimento da identidade e imagem do BACEN, e também um melhor e mais
intenso relacionamento com a sociedade.

Desta forma, fica a necessidade de melhoria da imagem como um motivador para o desenvolvimento da responsabilidade social da instituição, enfatizando o caráter funcionalista da responsabilidade social para a organização estudada.

Finalmente, o artigo de Friedman (1970) analisa a responsabilidade dos negócios sob a ótica puramente econômica. Friedman (1970) entende que os executivos são empregados que têm responsabilidades para com seus empregadores, os quais desejam auferir o máximo de lucros possível, dentro das regras estabelecidas pela sociedade, tanto as regras legais como as éticas. Como o executivo é agente dos proprietários, sua primeira responsabilidade é para com 
Responsabilidade social corporativa: uma discussão a respeito da epistemologia subjacente aos conceitos utilizados na área

eles e, portanto, se ele desejar fazer ações sociais, deve fazê-las com seu próprio tempo e dinheiro, e não com os recursos dos seus empregadores.

Se o executivo é contratado para trabalhar para os acionistas, afirma Friedman (1970), mas, ao invés disso, investe em ações sociais, então ele se torna um servidor público, não tendo sido eleito por um processo político, como deveria ser. Friedman (1970, p.7) enfatiza que "esta é a razão básica pela qual a doutrina da 'responsabilidade social' envolve a aceitação da visão socialista de que mecanismos políticos, e não de mercado, são a forma apropriada para determinar a alocação de recursos escassos para usos alternativos." No entendimento do autor, aqueles que investem recursos privados para finalidades públicas estão buscando fazer, por meio de procedimentos não democráticos, o que eles não conseguem fazer através de procedimentos democráticos.

Para Friedman (1970, p.11), "na prática a doutrina da responsabilidade social é frequentemente um envoltório para ações que são justificadas em outros campos, ao invés de ser uma razão para estas ações." O autor defende ainda que em muitos casos, as ações chamadas de responsabilidade social são baseadas meramente em interesses próprios das organizações, numa visão utilitária da ação social das empresas.

Há uma forte tentação em racionalizar estas ações como um exercício de
responsabilidade social. No presente clima de opinião, com a generalizada aversão
ao 'capitalismo', 'lucros', 'corporação sem alma', e por aí em diante, esta é uma
forma de a organização gerar boas ações com um tipo de 'subproduto' de gastos que
são inteiramente justificados por seu interesse próprio. (FRIEDMAN, 1970. p.11)

Friedman (1970) encerra o artigo com uma das frases mais utilizadas do trabalho dele nos estudos sobre responsabilidade social corporativa: "there is one and only one social responsibility of business - to use its resources and engage in activities designed to increase its profits so long as it stays within the rules of the game, which is to say, engages in open and free competition without deception or fraud." (FRIEDMAN, 1970. p.13)

\section{DISCUSSÃO}

A partir dos trechos destacados das obras referenciadas por Moretti e Campanário (2009), pôde-se proceder à análise epistemológica das assertivas enunciadas pelos autores a respeito dos motivos que levam as empresas à prática da responsabilidade social.

Inicialmente, considera-se importante destacar a grande diversidade da natureza dos oito trabalhos utilizados como universo de estudo. Temos livros didáticos, artigos de 
Rebeca de Moraes Ribeiro de Barcellos \& Eloise Livramento Dellagnelo periódicos acadêmicos, artigo de revista executiva, dissertação de mestrado, manual de referência e artigo de imprensa não especializada. Esta variedade de fontes utilizadas como base para a produção de artigos considerados científicos e publicados no maior evento científico de Administração no Brasil reforça nossa preocupação acerca do esclarecimento das bases epistemológicas utilizadas por estes trabalhos, explicitando uma fragilidade na construção do conhecimento sobre o assunto em parte da produção acadêmica nacional.

Destacamos ainda que nenhum dos trabalhos analisados explicita as bases epistemológicas sobre as quais foi construído. Os autores não definem (ou revelam) o arcabouço ideológico sobre o qual foram edificadas suas ideias, indo ao encontro da ressalva postulada por Garcia e Bronzo (2000, p.4), segundo os quais, "os estudos na administração não se inclinaram devidamente ao questionamento e à proposição de alternativas pragmáticas para o problema das relações de poder e dominação nos contextos organizacionais".

Verifica-se que apenas um dos trabalhos, o de Freeman (1999) possui base empírica e também racionalista. Apesar de não estar claro no artigo que a dedução foi o método utilizado para interpretação dos dados coletados pelos diferentes autores dos artigos apresentados por Freeman (1999), verifica-se que todos os artigos são resultados de pesquisas empíricas, efetuadas por meio de diferentes métodos, a partir das quais o autor pôde enunciar determinados aspectos da realidade organizacional no âmbito da responsabilidade social e do gerenciamento de stakeholders. O trabalho de Ventura (1999) é um estudo de caso, porém, as afirmações acerca da motivação das empresas para o exercício da responsabilidade social não foram alvo da pesquisa empírica, assim como os trabalhos de Ashley (2005), Ethos (2006), Porter (1995), Carrol (1979) e Friedman (1970). Tampouco se pode afirmar que são trabalhos fundamentados no racionalismo, pois, embora sejam fruto da reflexão e da estruturação do pensamento de seus autores, não objetam a comprovação da realidade por meio da realização de experimentos.

Em todos os trabalhos analisados verifica-se a perspectiva utilitarista dos autores com relação à responsabilidade social. No trabalho de Ashley (2005, p.8), por exemplo, afirma-se que a responsabilidade social é uma exigência para se sobreviver em meio à competição e que "tornou-se um diferencial fundamental para tornar as organizações mais produtivas e garantir o respeito do público e, enfim, sua própria viabilidade." Também são apontadas diversas vantagens que a empresa pode obter por meio da prática da responsabilidade social. Na mesma direção se percebe a visão de Porter (1995) quando o autor afirma que a melhoria 
Responsabilidade social corporativa: uma discussão a respeito da epistemologia subjacente aos conceitos utilizados na área

ambiental é uma oportunidade econômica e competitiva, que pode agregar valor ao consumidor e reduzir os custos para a empresa. Ainda neste sentido, Ventura (1999) apresenta que o exercício da responsabilidade social pode trazer ganhos de imagem à empresa, motivação dos funcionários e consolidação de valores de solidariedade entre estes. Para Friedman (1970), em muitos casos, as ações chamadas de responsabilidade social são baseadas meramente em interesses próprios das organizações, gerando "boas ações com um tipo de 'subproduto' de gastos que são inteiramente justificados por seu interesse próprio." (FRIEDMAN, 1970. p.11)

Pode-se argumentar que, de certa forma, a perspectiva utilitarista enfatiza uma tendência à "desubstantivização" do conceito de responsabilidade. Nas abordagens de responsabilidade social investigadas percebemos que os autores articulam uma apropriação da responsabilidade pelo social por parte das empresas. No entanto, diferentemente de uma responsabilidade pessoal, a qual estaria relacionada à resposta dos sujeitos pelos seus atos, o enfoque passa a ser mercadológico, utilitário, ligado a ganhos e vantagens.

Uma vez que não se encontram trabalhos empíricos, conforme concepção desenvolvida a partir do século XV, com exceção ao de Freeman (1999), não se pode afirmar a respeito do caráter positivista das bases teóricas em questão. O trabalho de Freeman (1999) apresenta resultados de pesquisas realizadas por meio do levantamento de dados e de experiências documentadas e descritas, a partir das quais se chegou às conclusões apresentadas. Porém, o mesmo não é observado nas demais obras em tela. Tal fato abre espaço para o questionamento acerca das bases sobre as quais se tem construído o arcabouço teórico do campo, levando-se em consideração que a produção reflexiva é importante, mas relevante também é a sua verificação prática e a reflexão estendida a outras vertentes e possibilidades, não somente à prescrição de "melhores jeitos de fazer" ou que vantagens as empresas obtêm com a prática.

Ao encontro desta constatação, verifica-se que todas as obras analisadas encaram a responsabilidade social sob uma perspectiva funcionalista, vendo na prática uma função para satisfazer a alguma necessidade da empresa, que pode ou não ir ao encontro de uma necessidade da sociedade. Para Ashley (2005), a adoção de padrões éticos atende à necessidade de a empresa ter boa imagem ou de demandas diretas do público. A responsabilidade social seria então uma resposta a pressões externas exercidas por um 
Rebeca de Moraes Ribeiro de Barcellos \& Eloise Livramento Dellagnelo

mercado crescentemente globalizado, no qual está se tornando hegemônica a visão de que é preciso haver ética e valores morais na condução dos negócios. O Instituto Ethos (2006) entende que o balanço social tem dois objetivos principais, que podem ser vistos como duas funções a cumprir na empresa: o de ser uma ferramenta de gestão, e também de diálogo. Nesta perspectiva, o balanço atende a necessidade de informação dos diversos públicos interessados, além de permitir à empresa constante avaliação de suas estratégias em direção à sustentabilidade. Também seria uma função do balanço estreitar as relações da empresa com seus stakeholders.

Na visão de Friedman (1970) a responsabilidade social é um desvio de função, ou seja, ao realizar ações sociais o executivo estaria se desviando de sua função dentro da organização, a qual seria gerar lucros aos acionistas. Também a organização estaria se desviando de sua função de auferir lucros, invadindo um espaço que não lhe pertence, e sim àqueles democraticamente eleitos para definir quais investimentos sociais devem ser realizados, sendo que estes devem ocorrer por meio da arrecadação de impostos e não dos desvios dos lucros privados.

A perspectiva dialética não aparece em nenhum dos trabalhados analisados. Nenhum dos autores abordou as contradições inerentes à ideia de responsabilidade social, tampouco a ideologia que suporta este movimento no meio empresarial. As questões de poder e autoridade, de dominação e influência, de inserção num sistema mundo, das relações centroperiferia, os conflitos inerentes ao conceito, entre outros aspectos, não foram objeto de análise em nenhuma das obras em destaque no presente estudo.

Resgatando as dimensões de análise a que se propôs este estudo, conclui-se que a) apenas uma das obras possui embasamento empírico para justificar os motivos pelos quais as empresas adotam práticas de responsabilidade social; b) a visão predominante acerca da Responsabilidade Social nestas pesquisas é utilitarista, buscando sempre demonstrar a busca de vantagens para as organizações com a execução de programas ou ações desta natureza; c) as obras não apresentam dados concretos sobre os quais se baseiam suas afirmativas, caracterizando os estudos por reflexões dos autores acerca do assunto, sobre uma base epistemológica não explícita; d) a perspectiva funcionalista também é dominante nas obras mais referenciadas nas pesquisas brasileiras, entendendo a responsabilidade social como uma função desempenhada pela empresa para o atendimento de alguma necessidade que, em geral 
Responsabilidade social corporativa: uma discussão a respeito da epistemologia subjacente aos conceitos utilizados na área

passa pela melhoria de sua imagem perante o público, melhoria do desempenho financeiro e conquista de vantagens competitivas; e e) as tensões inerentes aos conceitos, as contradições relacionadas às práticas, o olhar de outros sujeitos envolvidos que não empresas e executivos, o contexto de ordenação política e econômica no qual a discussão sobre o assunto ganha força não são mencionados em nenhuma das obras analisadas.

\section{CONSIDERAÇÕES FINAIS}

O presente estudo se propôs a analisar os fundamentos epistemológicos da produção brasileira em torno do tema Responsabilidade Social Corporativa, basicamente no que diz respeito às razões para adoção desta prática. Para tanto, utilizou-se o levantamento feito por Moretti e Campanário (2009), o qual apontou as bibliografias mais referenciadas nos Encontros Nacionais da Associação Nacional de Pós-Graduação em Administração.

Estas bibliografias foram analisadas, por meio de análise categorial, de acordo com categorias pré-definidas, permitindo verificar que a produção sobre o tema tem se baseado predominantemente numa visão utilitarista e funcionalista da responsabilidade social nas organizações, preocupando-se em elaborar reflexões não comprovadas empiricamente sobre as vantagens que a empresa pode obter por meio do exercício desta, bem como de sua função, a qual geralmente é vinculada à obtenção de ganhos estratégicos em termos de imagem, competitividade e redução de custos. O utilitarismo presente nas abordagens aponta para a desubstantivização do conceito de responsabilidade. A falta de verificação empírica levanta o questionamento acerca da validade científica das bases analisadas, alertando para a necessidade de um aprofundamento no campo, sob pena de manter-se a reprodução de discussões que podem estar desvinculadas da realidade organizacional.

É válido salientar que o modo de fazer ciência está indissociavelmente ligado aos padrões sociais vigentes, à gama de interesses que ronda a atividade científica e aos paradigmas estabelecidos que determinam métodos, meios, normas e padrões de reconhecimento e valorização. A ciência da Administração não difere das demais, e, portanto, está sujeita às mesmas condições, senão de forma mais enfática, tendo em vista que é uma ciência cuja tarefa tem sido fundamentar e reproduzir o sistema econômico vigente e o paradigma de atuação dominante.

REAd I Porto Alegre - Edição 74 - N 1 - jan/abr 2013 - p. 35-60 
Rebeca de Moraes Ribeiro de Barcellos \& Eloise Livramento Dellagnelo

As conclusões que se verificam a partir das análises realizadas, permitem inferir que uma parte importante da produção de conhecimento no campo da responsabilidade social corporativa no Brasil é fortemente influenciada pelo contexto do chamado paradigma vigente, no sentido aplicado por Souza Santos (1998), prevalecendo as formulações de caráter utilitarista e funcionalista no contexto dos estudos apresentados. Embora úteis e importantes para o campo de atuação em questão, a prevalência irrefletida de tais bases epistemológicas aponta para um reducionismo do campo, centrado na reprodução de fórmulas e roteiros de “como obter vantagens por meio da atuação social." Nas obras analisadas, a preocupação ética é uma resposta a uma demanda de mercado, e não um modo de operar de uma organização. A sua participação social é uma resposta a uma expectativa da sociedade, e não consciência da necessidade de um engajamento comunitário significativo. A preocupação ambiental é vista como uma oportunidade de inovação, agregação de valor e ganho de participação de mercado, e não um compromisso com a qualidade de vida das pessoas atual e futuramente.

Ressalta-se que as obras utilizadas foram publicadas, em sua maioria, na década de 90, quando o assunto ainda era tratado de forma incipiente no meio acadêmico e no campo a prática ainda se encontrava em fase de institucionalização, como aponta o estudo de Santos (2008). Neste contexto, é importante refletir que a produção acadêmica em torno de assuntos relativamente recentes tem seus méritos no sentido de abrir um novo campo de estudos, de iniciar a exploração deste campo, o que condiz com a forma mais descritiva e prescritiva encontrada nas obras analisadas. Por outro lado, o predomínio de bases utilitaristas e funcionalistas e a reprodução destas bases sem a apresentação de seus fundamentos pode também levar a uma miopia no campo, obscurecendo outras possibilidades de olhares sobre o assunto.

A análise das bases epistemológicas das obras mais utilizadas como referência no período mencionado corrobora com o pensamento de Moretti e Campanário (2009) os quais apontam para a existência de uma zona de conforto intelectual acerca do tema, apoiada em obras que reproduzem o conhecimento baseado em reflexões não comprovadas e que não incluem em suas perspectivas uma análise crítica e uma visão mais ampla dos fenômenos sociais. Por meio da análise empreendida, verifica-se que há espaço, e necessidade, de buscar outras bases para a análise deste fenômeno, se houver a intenção de compreendê-lo de forma mais abrangente, crítica e profunda. Por conta de uma construção de conhecimento mais comprometida com a realidade social na qual a administração está inserida, afirma-se que é 
Responsabilidade social corporativa: uma discussão a respeito da epistemologia subjacente aos conceitos utilizados na área

necessário partir para a compreensão das entrelinhas, das relações dialéticas que permeiam a atuação social das empresas, dos conflitos de interesses que cercam o tema, das relações de poder que as empresas estabelecem com outras organizações, inclusive o Estado e a sociedade civil, verificando as consequências reais das práticas empresariais sobre os seus diversos campos de influência.

\section{REFERÊNCIAS}

ASHLEY, Patricia. Ética e responsabilidade social nos negócios. São Paulo: Saraiva, 2001.

BACON, Francis. Novum Organum ou Verdadeiras indicações acerca da interpretação da natureza: nova atlântida. 2.ed. São Paulo: Abril Cultural, 1979.

BARDIN, Laurence. Análise de conteúdo.

BUCKLEY, W. A sociologia e a moderna teoria dos sistemas. São Paulo: Cultrix, 1967.

CARROL, Anchie B. A three-dimensional conceptual model of corporate performance. Academy of Management Review. v.4, p. 497-505, 1979.

DESCAMPS, C. As ideias filosóficas contemporâneas na França (1960-1985). Rio de Janeiro: Jorge Zahar, 1991.

DESCARTES, René. Discurso do método ; Meditações ; Objeçoes e respostas ; As paixoes da alma ; Cartas. 2.ed. São Paulo: Abril Cultural, 1979.

DEMO, Pedro. Metodologia científica em ciências sociais. São Paulo: Atlas, 1985.

DENZIN, N. K.; LINCOLN, Y. S. Introdução: a disciplina e a prática da pesquisa qualitativa. In: DENZIN, N. K.; LINCOLN, Y. S. (orgs.) O planejamento da pesquisa qualitativa: teorias e abordagens. 2. ed. Porto Alegre: Artmed, 2006. p. 15-41.

DURKHEIM, Émile. Durkheim, coleção os pensadores. São Paulo: Abril Cultural, 1978. 
Rebeca de Moraes Ribeiro de Barcellos \& Eloise Livramento Dellagnelo

EVANS-PRITCHARD, E. Desenvolvimento teórico posterior. In: Antropologia social. Lisboa: Edições 70, 1972.

FOULQUIÉ, Paul. A dialética. Lisboa: Europa-América, cap. 1, 1978.

FREEMAN, R. Edward. Stakeholders, social responsibility, and performance: empirical evidence and theoretical perspectives. Academy of Management Journal. v.42, n.5, oct. 1999.

FREIRE, Robson, et al. Responsabilidade social corporativa: evolução da produção científica. In: Congresso nacional de excelência em gestão, 4., 2008, Niterói: 2008.

FRIEDMAN, Milton. The social responsability of businnes is to increase its profits. New York Times Magazine, September, 1970.

GARCIA, F. C. e BRONZO, M. As bases epistemológicas do pensamento administrativo convencional e a crítica à teoria das organizações. In: Encontro Nacional de Estudos Organizacionais, 1., 2000, Curitiba. Anais... Curitiba : Anpad, 2000.

GUBA, E. LINCOLN, Y. Competing paradigms in qualitative research. In.: DENZIN, N. LINCOLN, Y. Handbook of Qualitative Research. London: Sage, 1994.

GURVITCH, Georges. Caracterização prévia da dialética. In: Dialética e sociologia. São Paulo: Vértice, 1987.

INSTITUTO ETHOS. Guia de elaboração do Balanço Social-2002. Disponível em WWW.ethos.org.br. Acesso em 28.11.2009.

JAPIASSU, H. Introdução ao pensamento epistemológico. 6. Ed. São Paulo: Francisco Alves, 1991.

LAPASSADE, Georges. Grupos, organizações e instituições. Rio de Janeiro, F. Alves: 1977.

LEFEBVRE, Henri. Lógica formal. Lógica dialética. Rio de Janeiro: Civilização Brasileira, 1983.

REAd I Porto Alegre - Edição 74 - N 1 - jan/abr 2013 - p. 35-60 
Responsabilidade social corporativa: uma discussão a respeito da epistemologia subjacente aos conceitos utilizados na área

MALINOWSKI, B. A teoria funcional. In: Uma teoria científica da cultura. Rio de Janeiro: Zahar, 1970.

MELO NETO, F. P., FROES, C. Responsabilidade social e cidadania empresarial. Rio de Janeiro: Qualitymark, 1999.

MORETTI, Sergio, CAMPANÁRIO, Milton. A produção intelectual brasileira em Responsabilidade Social Empresarial: RSE sob a ótica da bibliometria. RAC. v.13, art.5, p.68-86. Curitiba: ANPAD, junho, 2009.

PARSONS, Talcott. Sugestões para um tratado sociológico da teoria de organização. In: Etzioni, A. (org.), Organizações complexas. São Paulo: Atlas, 1967.

POPPER, Karl. A lógica da investigação científica. In: Karl Popper, coleção Os Pensadores. São Paulo: Abril Cultural, 1980.

PORTER, Michael. Green and Competitve: ending the stalemate. Harvard Businnes Review. v. 73, n. 5, p. 120-134. Sep/Oct., 1995.

RADCLIFFE-BROWN, A. Sobre o conceito de função em ciências sociais. In: Estrutura e função na sociedade primitiva. Petrópolis: Vozes, 1973.

SANTOS, Gilmar José dos. Cidadania Corporativa ou Ferramenta de Legitimação? Uma Análise da Institucionalização das Práticas de Responsabilidade Social. In: Encontro Nacional da ANPAD, 32., 2008, Rio de Janeiro. Anais... Rio de Janeiro: Anpad, 2008.

SOUZA SANTOS, Boaventura. Um discurso sobre as ciências na transição para uma ciência pós-moderna. Estudos Avançados, n. 3. Maio/agosto, 1998.

VENTURA, E. Responsabilidade social das organizações: estudo de caso no Banco Central do Brasil. Dissertação (Mestrado em Administração) - Fundação Getúlio Vargas/EBAPE, Rio de Janeiro, 1999.

VIEIRA, M. Por uma boa pesquisa (qualitativa) em administração. In: VIEIRA, M.;

ZOUAIN, D. Pesquisa qualitativa em administração. Rio de Janeiro: FGV Editora.2004.

REAd I Porto Alegre - Edição 74 - N 1 - jan/abr 2013 - p. 35-60 